\title{
Decline in Psychotic Symptoms in Addition to Cardiac and Metabolic Safety with Cariprazine After Poor Response to Previous Antipsychotic Treatments - A Series of Two Cases
}

This article was published in the following Dove Press journal:

Neuropsychiatric Disease and Treatment

Helge HO Müller ${ }^{1,2}$

Sebastian Moeller ${ }^{1}$

'Lehrstuhl für Integrative Psychiatrie und Psychotherapie, Universität Witten/ Herdecke gGmbH, Witten, 58448,

Germany; ${ }^{2}$ Gemeinschaftskrankenhaus Herdecke, Abteilung für Psychiatrie und Psychotherapie, Herdecke, Germany
Correspondence: Helge HO Müller Lehrstuhl für Integrative Psychiatrie und Psychotherapie, Universität Witten/ Herdecke $\mathrm{gGmbH}$, Alfred-HerrhausenStraße 50, Witten, 58448, Germany

Tel $+49233062-3167$

Fax +49233062-3338

Email helge.mueller@uni-wh.de

\begin{abstract}
Cariprazine is a highly effective antipsychotic medication of the latest generation. Due to its special receptor profile with D2/D3 partial agonism and high D3 affinity, the use of cariprazine is particularly justified in negative psychotic symptomatic and cardiac prestressed patients or in patients with weight management problems. In this case series, two cases and the outcomes during the switch to cariprazine treatment under these conditions are described.
\end{abstract}

Keywords: drug-induced, schizophrenia, negative symptoms, side effects, weight, cardiac safety

\section{Introduction}

Schizophrenia is a chronic, heterogeneous and often severe mental disorder that may have debilitating long-term outcomes. Lifetime prevalence is estimated to be approximately $1 \%$ worldwide. ${ }^{1,2}$ Symptoms mainly comprise three domains. Positive symptoms, such as, hallucinations, delusions, and persecution, and negative symptoms, such as emotional withdrawal, blunted affect and passive social withdrawal, may be present. Moreover, cognitive symptoms, such as impaired perception, learning, thinking, and memorizing, may occur. ${ }^{1-3}$ Antipsychotic treatment may be complicated by patient comorbidities, including structural cardiac abnormalities, cardiac arrhythmias, obesity and others. In addition, many antipsychotic medications have only a limited effect on negative symptoms and may lead to undesirable side effects, including weight gain, cardiac QT time prolongation and others. ${ }^{1,2,4}$ Thus, an antipsychotic drug with better effects, especially on negative schizophrenic symptoms, and few side effects would be highly desirable.

Cariprazine, approved in 2017 in the EU, is a new antipsychotic agent within the therapeutic armamentarium in clinical psychiatry. ${ }^{3,5-7}$ Cariprazine is a dopamine D3/D2 receptor agonist and a serotonin 5-HT1A receptor partial agonist, among other receptors. Cariprazine has the highest D3 receptor affinity of all newgeneration antipsychotic drugs. ${ }^{3,8-11}$

Here, we present two cases of schizophrenic patients who have been successfully treated with cariprazine despite a long patient history and comorbidities. 


\section{Case I}

A 38-year-old female patient had been followed-up for schizophrenia for approximately 10 years. Her medical history included obesity (body mass index (BMI) 28.7) and hypertension. In addition, the patient underwent surgical mitral valve reconstruction and left atrial appendage exclusion 3 years prior due to pronounced myxomatous degeneration of both mitral valve leaflets.

The patient had been treated with amisulpride (200-200-200 mg), benperidol (2-0-3 mg), olanzapine (5-0-5 mg) and clozapine (doses up to $200 \mathrm{mg} / 24 \mathrm{~h}$ ), each for an adequate period of time. However, she did not properly respond to any of these medications. Moreover, she partially suffered from significant intolerable extrapyramidal motor and/or anticholinergic effects leading to the reduction or discontinuation of the drugs. The patient also showed typical negative symptoms such as significant affect flattening, prolonged response latency and a psychosis-related short-term memory disorder.

On admission, she had been taking $800 \mathrm{mg}$ quetiapine and $600 \mathrm{mg}$ amisulpride. In addition to the antipsychotic medication, she took ramipril $5 \mathrm{mg}$ and aspirin $100 \mathrm{mg}$ as daily doses.

Treatment success was evaluated using the Positive and Negative Syndrome Scale (PANSS, ${ }^{12}$ and Clinical Global Impressions Scale (GCI-S, ${ }^{13}$ scores. The PANSS total score at admission was 190 for the general psychopathology scale, with the main affections being excitement, grandiosity, and suspiciousness/persecution for the positive symptom scale and affection in all domains for the negative symptom scale.

After a premedication wash-out phase over four days (two days of half doses, followed by the suspension of the former medication), we administered cariprazine with a starting dose of $1.5 \mathrm{mg}$ per day. The patient did not report any side effects during the treatment course. After 4 days, the doses was increased to $3 \mathrm{mg}$. After another week, the dose was increased up to $4.5 \mathrm{mg}$. Regularly, electrocardiogram (ECG) recordings were unremarkable, with a bradycardia sinus rhythm and a QTc time between 405 and $440 \mathrm{~ms}$. Both the CGI-S and the PANSS scores improved significantly during the observation period (a CGI-S score of 3 and a PANSS total score of 80 before discharge).

After 10 weeks, the patient was regularly discharged from in-hospital treatment. In the outpatient setting, medication with cariprazine at a dose of $4.5 \mathrm{mg}$ was continued (with consistently stable PANSS scores; 70 maximum, 100/total score). Regular laboratory and ECG parameters were consistently inconspicuous. Remarkably, no further antipsychotic medication was required. The current stable follow-up now extends over 2 years without any indication of a recurrence of the underlying psychotic disease.

\section{Case 2}

The 34-year-old female patient was hospitalized because of a relapse of psychotic symptoms, with disjointed and incoherent thinking as well as self-disturbances in the form of thought spread and withdrawal. The physical examination results at the time of hospital admission showed a BMI of 34.5 (weight: 102 kilograms, height: $172 \mathrm{~cm}$ ), arterial hypertension, appendectomy 10 years before admission, nulliparous and no other concomitant somatic diseases. Addiction anamnesis except for nicotine consumption of 20 cigarettes/d was unremarkable. In previous hospital stays, florid hallucinatory episodes in the form of commenting and dialogizing voices as well as negative symptoms that existed at the same time were documented. Family anamnesis revealed a grandmother with paranoid schizophrenia but was otherwise unremarkable. Various previous antipsychotic pharmacological therapy trials resulted in either a lack of efficacy in the patient (with a cardiovascular risk profile; daily maximum dose of $800 \mathrm{mg}$ quetiapine and aripiprazole at a daily dose of $10 \mathrm{mg}$ ) or significant adverse effects (haloperidol daily dose $10 \mathrm{mg}$, extrapyramidal motor symptoms). The PANSS total score at admission was 170 (with clear dominance of the negative symptom constellations (each severe in blunted affect, emotional withdrawal and poor rapport); the CGI-S score (severity) was 5 (significantly ill).

When admitted to our clinic (first stay, pretreatments in other clinics), combination therapy consisted of risperidone 2-0-0-2 $\mathrm{mg}$ and olanzapine $0-0-0-5 \mathrm{mg}$.

During the treatment, the medication was switched from combination therapy of risperidone and olanzapine to cariprazine. Both positive and negative psychotic symptoms improved, and the patient received an accompanying nutritional consultation that led to significant weight loss $(-14 \mathrm{~kg})$ and increased patient satisfaction during the hospital stay.

The treatment course was marked in particular by the following points: the controlled conversion of the previous medication to monotherapy with cariprazine under inpatient treatment and the management of the symptoms and 
undesirable effects of the previous medication (especially short-term memory disorder and obesity).

After the usual preliminary examinations (physical examination, weighing, routine blood workup, ECG, psychological initial diagnosis and therapy target definition), the dose of olanzapine was first halved for three days and then discontinued completely.

Lorazepam was administered at a daily maximum dose of $2 \mathrm{mg}$ to reduce possible anxiety and restlessness within the scope of the discontinuation.

In addition to psychotherapy (main focus of compliance promotion and education on psychosis), the patient received structured sports therapy and nutritional dietary support as well as occupational therapy and sociotherapeutic multimodal treatment tailored to the patient.

In the third week of the inpatient stay, the transition from risperidone to cariprazine began. The starting dose of cariprazine was $1.5 \mathrm{mg}$, which was followed for two days and then increased to a $3 \mathrm{mg}$ daily dose. This dose was followed for three more weeks, during which the discontinuation of risperidone occurred (halving the dose for ten days, then discontinuing the medication). After risperidone interruption, cariprazine was increased to $4.5 \mathrm{mg}$. During the entire inpatient course, laboratory and ECG checks were carried out twice a week, as well as a collection of psychopathological findings and psychopathological examinations using the CGI-S and PANSS. In addition, the patient was weighed regularly. In total, the patient was hospitalized for eight weeks. Both the CGI-S and the PANSS scores improved significantly during the inpatient observation period (to a CGI-S score of 3 and a PANSS total score of 70 shortly before dismissal).

Thereafter, a connection was made to our psychiatric clinic. The patient has been and is regularly seen and reexamined there. Medication with cariprazine at a therapeutic dose of $4.5 \mathrm{mg}$ has continued at an unchanged dosage (with consistently stable PANSS scores; 70 maximum, 90/total score).

That there have been no objectively or subjectively perceived undesirable effects of monotherapy with cariprazine during the entire inpatient treatment and after discharge is particularly pleasing; at the same time, a remarkable weight reduction of $16 \mathrm{~kg}$ was achieved over the entire inpatient and outpatient course. The patient regularly participated in an outpatient sports group and nutrition counseling. The current stable follow-up now extends over half a year, without any indication of a recurrence of the underlying psychotic disease.

\section{Discussion}

Cariprazine is a highly effective antipsychotic drug of the newest generation. The efficacy extends to the entire schizophrenia symptom spectrum, particularly to negative symptoms. ${ }^{4,6,9,11}$ In addition, the novel molecule and its receptor profile offer a range of advantages for clinical use. In particular, the undesirable consequences, such as metabolic and cardiovascular effects, ${ }^{5-7,14}$ described for other newer preparations are rare. ${ }^{3,9,11,15}$ The efficacy extends to the entire schizophrenia symptom spectrum. ${ }^{2,4,11}$ This efficacy seems to be mainly due to the receptor profile, with D2/ D3 partial agonism and high D3 affinity. Cariprazine has the highest D3 receptor affinity of any of the newer antipsychotics. $^{4-7}$

The particular metabolic-related aspects of the cases reported here occurred under previous medications. Cognitive disorders and negative symptoms also improved in the course of the process. After the switch to cariprazine, an improvement in psychotic symptoms with subsequent stable inpatient and outpatient symptom control was achieved; simultaneously, cardiovascular risk profile improvement was achieved that had a particularly positive consecutive effect. These clinical effects are in line with recent findings where cariprazine was used as an add-on therapy ${ }^{16}$ and systematic review evidence. ${ }^{10,17}$

Cariprazine is an effective and well tolerated antipsychotic, especially in patients with paranoid schizophrenia, negative symptoms and a high cardiovascular risk profile. ${ }^{7,10,11,14}$ Due to partial agonism at dopamine D2/D3 receptors, preferential binding to D3 receptors, and partial agonism at serotonin 5-HT1A receptors, the propensity for extrapyramidal side effects is lower than that for other antipsychotics (Table 1). The same mode of action is supposed to be responsible for the (beneficial) effects on weight gain management. ${ }^{8,10,11}$ On the basis of this evidence for beneficial effects of cariprazine treatment, a critical examination of possible use of the drug in everyday clinical practice should be considered, and cariprazine should be offered to all patients with the appropriate indication. The cases described here underline these mid- to long-term effects for six months and two years of cariprazine monotherapy.

In particular, the positive effects and safety of cariprazine in a long-term treatment course, as described in this case series, should be systematically evaluated in further systematic trials. 
Table I Receptor Profile of Cariprazine with Receptor Activity and Subsequent Clinical Effects and Side Effects

\begin{tabular}{|l|l|l|}
\hline Receptor & Activity & Clinical Effects/Side Effects \\
\hline D3 & Partial agonist & $\begin{array}{l}\text { Improvement of psychotic symptomatology positive, negative and depressive symptoms - improvement pro- } \\
\text { cognitive properties little adverse effects, eg, extrapyramidal symptoms or hyperprolactinemia }\end{array}$ \\
\hline D2 & Partial agonist & $\begin{array}{l}\text { Improvement of psychotic symptomatology positive symptoms - improvement little adverse effects, eg, } \\
\text { extrapyramidal symptoms or hyperprolactinemia }\end{array}$ \\
\hline $5-\mathrm{HT}_{\text {IA }}$ & Partial agonist & Negative and depressive symptoms - improvement \\
\hline $5-\mathrm{HT}_{2 \mathrm{~A}}$ & Antagonist & Risk of extrapyramidal symptoms - reduction \\
\hline $5-\mathrm{HT}_{2 \mathrm{~B}}$ & Antagonist & Depressive symptoms - improvement pro-cognitive properties \\
\hline $5-\mathrm{HT}_{2 \mathrm{C}}$ & Antagonist & Depressive symptoms - improvement \\
\hline $5-\mathrm{HT}_{7}$ & Antagonist & Depressive symptoms - improvement pro-cognitive properties \\
\hline
\end{tabular}

\section{Abbreviations}

D2/D3, dopamine receptors 2/3; EU, European Union; 5-HT, serotonin receptor; BMI, body mass index; mg, milligram; h, hours; PANSS, Positive and Negative Syndrome Scale; GCIS, Clinical Global Impressions Scale; ECG, electrocardiogram; ms, milliseconds; cm, centimeter; d, day.

\section{Data Sharing Statement}

The datasets generated during and analyzed during the current study are available from the corresponding author on reasonable request.

\section{Consent for Publication}

Patients have given their consent to publication. No institutional approval was required to publish the case details.

\section{Author Contributions}

Both authors of this article:

1. Made a significant contribution to the work reported, whether that is in the conception, study design, execution, acquisition of data, analysis and interpretation, or in all these areas.

2. Have drafted or written, or substantially revised or critically reviewed the article.

3. Have agreed on the journal to which the article will be submitted.

4. Reviewed and agreed on all versions of the article before submission, during revision, the final version accepted for publication, and any significant changes introduced at the proofing stage.

5. Agree to take responsibility and be accountable for the contents of the article.

\section{Funding}

The open access fee for publication of this case series is funded by Recordati.

\section{Disclosure}

The authors report no conflicts of interest in this work.

\section{References}

1. Owen MJ, Sawa A, Mortensen PB. Schizophrenia. Lancet. 2016;388 (10039):86-97. doi:10.1016/S0140-6736(15)01121-6

2. Charlson FJ, Ferrari AJ, Santomauro DF, et al. Global epidemiology and burden of schizophrenia: findings from the global burden of disease study 2016. Schizophr Bull. 2018;44(6):1195-1203. doi:10.1093/schbul/sby058

3. Earley W, Guo H, Daniel D, et al. Efficacy of cariprazine on negative symptoms in patients with acute schizophrenia: a post hoc analysis of pooled data. Schizophr Res. 2019;204:282-288. doi:10.1016/j. schres.2018.08.020

4. Corponi F, Fabbri C, Bitter I, et al. Novel antipsychotics specificity profile: a clinically oriented review of lurasidone, brexpiprazole, cariprazine and lumateperone. Eur Neuropsychopharmacol. 2019;29 (9):971-985. doi:10.1016/j.euroneuro.2019.06.008

5. Calabrese F, Tarazi FI, Racagni G, Riva MA. The role of dopamine D (3) receptors in the mechanism of action of cariprazine. CNS Spectr. 2020;25(3):343-351. doi:10.1017/S109285291900083X

6. Chhatlani A, Farheen SA, Setty MJ, Tampi RR. Use of cariprazine in psychiatric disorders: a systematic review. Ann Clin Psychiatry. 2018;30(4):326-334.

7. Nasrallah HA, Earley W, Cutler AJ, et al. The safety and tolerability of cariprazine in long-term treatment of schizophrenia: a post hoc pooled analysis. BMC Psychiatry. 2017;17(1):305. doi:10.1186/s12888-0171459-z

8. Citrome L. Cariprazine for the treatment of schizophrenia: a review of this dopamine D3-preferring D3/D2 receptor partial agonist. Clin Schizophr Relat Psychoses. 2016;10(2):109-119. doi:10.3371/19351232-10.2.109

9. Cooper H, Mishriky R, Reyad AA. Efficacy and safety of cariprazine in acute management of psychiatric disorders: a meta-analysis of randomized controlled trials. Psychiatr Danub. 2020;32(1):36-45. doi: $10.24869 /$ psyd.2020.36 
10. Orsolini L, De Berardis D, Volpe U. Up-to-date expert opinion on the safety of recently developed antipsychotics. Expert Opin Drug Saf. 2020;19(8):981-998. doi:10.1080/14740338.2020.1795126

11. Leucht S, Crippa A, Siafis S, Patel MX, Orsini N, Davis JM. Doseresponse meta-analysis of antipsychotic drugs for acute schizophrenia. Am J Psychiatry. 2020;177(4):342-353. doi:10.1176/ appi.ajp.2019.19010034

12. Kay SR, Fiszbein A, Opler LA. The positive and negative syndrome scale (PANSS) for schizophrenia. Schizophr Bull. 1987;13 (2):261-276. doi:10.1093/schbul/13.2.261

13. Guy W. Clinical Global Impressions ECDEU Assessment Manual for Psychopharmacology. Rockville: National Institute of Mental Health; 1976:218-222.

14. Ijaz S, Bolea B, Davies S, et al. Antipsychotic polypharmacy and metabolic syndrome in schizophrenia: a review of systematic reviews. BMC Psychiatry. 2018;18(1):275. doi:10.1186/s12888-0181848-y
15. Earley W, Durgam S, Lu K, Laszlovszky I, Debelle M, Kane JM. Safety and tolerability of cariprazine in patients with acute exacerbation of schizophrenia: a pooled analysis of four phase II/III randomized, double-blind, placebo-controlled studies. Int Clin Psychopharmacol. 2017;32(6):319-328. doi:10.1097/ YIC.0000000000000187

16. De Berardis D, Rapini G, Olivieri L, et al. Cariprazine add-on in inadequate clozapine response: a report on two cases. Clin Psychopharmacol Neurosci. 2021;19(1):174-178. doi:10.9758/ cpn.2021.19.1.174

17. De Berardis D, Orsolini L, Iasevoli F, et al. The novel antipsychotic cariprazine (RGH-188): state-of-the-art in the treatment of psychiatric disorders. Curr Pharm Des. 2016;22(33):5144-5162. doi:10.2174/1381612822666160701084447

\section{Publish your work in this journal}

Neuropsychiatric Disease and Treatment is an international, peerreviewed journal of clinical therapeutics and pharmacology focusing on concise rapid reporting of clinical or pre-clinical studies on a range of neuropsychiatric and neurological disorders. This journal is indexed on PubMed Central, the 'PsycINFO' database and CAS, and is the official journal of The International Neuropsychiatric Association (INA). The manuscript management system is completely online and includes a very quick and fair peer-review system, which is all easy to use. Visit http://www.dovepress.com/testimonials.php to read real quotes from published authors. 